\title{
Physical Properties of Sphagnum Peat-based Root Substrates Amended with Perlite or Parboiled Fresh Rice Hulls
}

\author{
Michael R. Evans ${ }^{1,3}$ and Mary M. Gachukia ${ }^{2}$
}

ADDITIONAL INDEX WORDS. potting soil, total pore space, air-filled pore space, water-filled pore space, water-holding capacity, bulk density

\begin{abstract}
SUMMARY. Ten substrates were formulated by blending perlite or parboiled fresh rice hulls $(\mathrm{PBH})$ to produce root substrates (substrates) that contained either $20 \%$, $30 \%, 40 \%, 50 \%$, or $60 \%$ (by volume) perlite or $\mathrm{PBH}$, with the remainder being sphagnum peatmoss. All substrates containing $\mathrm{PBH}$ had higher total pore space than substrates containing an equivalent amount of perlite. As the percentage perlite increased from $20 \%$ to $60 \%$, the total pore space decreased. The total pore space increased as the amount of $\mathrm{PBH}$ increased to $50 \%$ and then decreased as the amount of $\mathrm{PBH}$ increased from $50 \%$ to $60 \%$. The air-filled pore space was not different between substrates containing $20 \%$ perlite or $\mathrm{PBH}$. However, the air-filled pore space was higher in $\mathrm{PBH}$-containing substrates than in equivalent perlitecontaining substrates when the amount of $\mathrm{PBH}$ or perlite was at least $40 \%$. As the amount of perlite or $\mathrm{PBH}$ was increased, the air-filled pore space increased, but the rate of increase was higher for $\mathrm{PBH}$-containing substrates. The $20 \% \mathrm{PBH}$ containing substrate had a higher water-holding capacity than the $20 \%$ perlitecontaining substrate. However, at $30 \%$ or higher $\mathrm{PBH}$, the $\mathrm{PBH}$-containing root substrates had a lower water-holding capacity than equivalent perlite-containing substrates. As the percentage perlite or $\mathrm{PBH}$ was increased, the water-holding capacity decreased, but at a higher rate in PBH-containing substrates than in perlite-containing substrates. For all substrates except those containing $40 \% \mathrm{PBH}$ or perlite, substrates containing $\mathrm{PBH}$ had lower bulk densities than equivalent perlite-containing substrates. The differences in bulk densities were not great enough to be of practical significance. Inclusion of $\mathrm{PBH}$ in the substrate provided for drainage and air-filled pore space as did perlite. However, less PBH would be required in a substrate to provide the same air-filled pore space as perlite when more than $20 \%$ perlite or $\mathrm{PBH}$ is used.
\end{abstract}

$\mathrm{R}$ oot substrates (substrates) are commonly used in the production of containerized greenhouse and nursery crops (Nelson, 2003). Substrates are formulated from various inorganic and organic components to provide suitable physical and chemical properties as required by the specific crop and growing conditions (Bunt, 1988). An important physical property of substrates is air-filled pore space. Air-filled pores allow for drainage and gas exchange between the root environment and the outside atmosphere (Bunt, 1988). Various materials are used to provide, at least in part, for air-filled pore space in substrates, with one of the most common being perlite (Boertje and Arnold Bik, 1975; Bunt, 1988).

Perlite is an inorganic, expanded aluminosilicate of volcanic origin (Nelson, 2003) and it is produced by mining the ore, grinding the crude ore to the desired particle size, and heating it to temperatures of up to $982{ }^{\circ} \mathrm{C}$. Heating causes the ore to expand from four to 20 times its original volume, resulting in a lightweight white porous particle (Hanan, 1998). Because of the costs associated with mining, transportation, and heating, perlite is a relatively expensive substrate component. In addition to its cost, in its dry state perlite produces a siliceous dust that is classified as an eye and lung irritant. Substrate components that are lower in cost, do not have potential health issues, and could provide for air-filled pore space in the substrate would be beneficial to the nursery and greenhouse crops industries.

Some potential alternative components to perlite (e.g., shredded rubber, ground bovine bone) have undesirable chemical properties (Evans, 2004; Evans and Harkess, 1997) such as high $\mathrm{pH}$, high electrical conductivity, or phytotoxic levels of one more mineral nutrients. Other materials evaluated as potential alternatives to perlite are either too expensive or have unacceptably high bulk densities (e.g., calcined clay aggregates, gravel), which resulted in unacceptably high shipping costs.

Parboiled fresh rice hulls $(\mathrm{PBH})$ are a milling coproduct of the rice industry and comprise $\approx 20 \%$ of the rice grain at harvest. Parboiled fresh rice hulls are obtained as a result of a steaming process and are therefore free of viable weed seed. Evans and Gachukia (2004) demonstrated that $\mathrm{PBH}$ could be successfully used as an alternative to perlite in the root substrate for the production of several ornamental species. However, the physical properties of $\mathrm{PBH}$-amended sphagnum peat-based substrates compared with those amended with perlite have not been reported. Additionally, how increasing amounts of PBH in the substrate affects the physical properties of the substrate has not been reported.

The objectives of this study were to determine and compare total pore space ( $\%$ by volume), air-filled pore space (\% by volume), water-holding capacity ( $\%$ by volume and weight per weight), and bulk density (weight per volume) of sphagnum peat-based substrates amended with various amounts of $\mathrm{PBH}$ or perlite, and to determine how the amount of $\mathrm{PBH}$ or perlite affects these physical properties.
Department of Horticulture, University of Arkansas, 315 Plant Science Building, Fayetteville, AR 72701

This project was supported by Riceland Foods, Stuttgart, Ark., and the University of Arkansas Division of Agriculture.

${ }^{1}$ Associate Professor.

${ }^{2}$ Graduate Research.

${ }^{3}$ Corresponding author. E-mail: mrevans@uark.edu.

\begin{tabular}{llll}
\hline $\begin{array}{l}\text { Units } \\
\text { To convert U.S. to SI, } \\
\text { multiply by }\end{array}$ & U.S. unit & SI unit & $\begin{array}{l}\text { To convert SI to U.S., } \\
\text { multiply by }\end{array}$ \\
\hline 29.5735 & $\mathrm{fl} \mathrm{oz}$ & $\mathrm{mL}$ & 0.0338 \\
2.5400 & inch $(\mathrm{es})$ & $\mathrm{cm}$ & 0.3937 \\
1.7300 & $\mathrm{Oz} / \mathrm{inch}^{3}$ & $\mathrm{~g} \cdot \mathrm{cm}^{-3}$ & 0.5780 \\
$\left({ }^{\circ} \mathrm{F}-32\right) \div 1.8$ & ${ }^{\circ} \mathrm{F}$ & ${ }^{\circ} \mathrm{C}$ & $\left(1.8 \times{ }^{\circ} \mathrm{C}\right)+32$
\end{tabular}

Horfechnology · July-September 2007 17(3) 


\section{Materials and methods}

Parboiled fresh rice hulls were obtained from Riceland Foods (Stuttgart, Ark.). Parboiled fresh rice hulls were dried and bagged immediately after parboiling and drying without being stored outside. Horticultural perlite and sphagnum peat were obtained from Sun Gro Horticulture (Bellevue, Wash.). Ten substrates were formulated by blending perlite or $\mathrm{PBH}$ in a rotary mixer for $1 \mathrm{~min}$ at $50 \mathrm{rpm}$ to produce root substrates that contained either $20 \%, 30 \%, 40 \%, 50 \%$, or $60 \%(\mathrm{v} / \mathrm{v})$ perlite or $\mathrm{PBH}$, with the remainder being sphagnum peat.

The root substrates were airdried in a greenhouse at 32 to $35^{\circ} \mathrm{C}$ until they no longer lost weight over a 24 -h period. The samples were rewetted with deionized water to a moisture level of $60 \%$ (wt/wt). They were then placed into sealed plastic bags and allowed to equilibrate for $1 \mathrm{~d}$ to attain moisture uniformity. Substrates were packed into $350-\mathrm{mL}$ porometers $(3 \times 3$-inch aluminum core), and total porosity (by volume), air-filled pore space (by volume), waterholding capacity (by volume), and bulk density (weight per volume) were determined using procedures described by Bilderback and Fonteno (1993) and Byrne and Carty (1989).

Five replications of each root substrate were evaluated. Single-df contrasts were conducted for each of the physical properties to determine whether significant differences occurred between root substrates containing equivalent amounts of perlite or PBH. Regression analysis was performed to determine how increasing amounts of perlite or $\mathrm{PBH}$ affected the root substrate physical properties. The best models describing the parameters were determined by evaluating a combination of the data values versus predicted values, residual values versus a zero reference line, and the $R^{2}$ values for each model.

\section{Results and discussion}

Total pore space in perlite-containing substrates ranged from $71.5 \%$ to $79.4 \%$ whereas total pore space in $\mathrm{PBH}$-containing substrates ranged from $82.1 \%$ to $86.7 \%$ (Table 1). All substrates containing $\mathrm{PBH}$ had more total pore space than substrates containing an equivalent amount of perlite. As the percentage perlite increased from $20 \%$ to $60 \%$, the total pore space decreased (Fig. 1), following the model $\mathrm{y}=77+11 \mathrm{x}-0.0035 \mathrm{x}^{2}\left(R^{2}=\right.$ $0.71)$. The total pore space increased as the amount of $\mathrm{PBH}$ increased to $50 \%$, and then decreased as the amount of $\mathrm{PBH}$ increased to $60 \%$. However, the change in total pore space as $\mathrm{PBH}$ increased was relatively small and followed the model $\mathrm{y}=70.1+$ $0.84 \mathrm{x}-0.0 \mathrm{~lx}^{2}\left(R^{2}=0.76\right)$.

The decrease in total pore space of perlite-containing substrates could be attributed to perlite having a total pore space of $74 \%$, which was lower than that for sphagnum peat at $84 \%$ (Hanan, 1998). Likewise, the small change in total pore space with increasing amounts of $\mathrm{PBH}$ could be attributed to $\mathrm{PBH}$ having a total pore space of $82 \%$, which was similar to the total pore space of sphagnum peat.

Air-filled pore space ranged from $9.5 \%$ to $12.7 \%$ for perlite-containing root substrates and $11.5 \%$ to $37.8 \%$ for $\mathrm{PBH}$-containing substrates (Table 1 ).

Table 1. Physical properties of sphagnum peat-based root substrates amended with perlite or parboiled fresh rice hulls $(\mathrm{PBH})$.

\begin{tabular}{|c|c|c|c|c|c|}
\hline $\begin{array}{l}\text { Substrate } \\
\text { composition }^{\mathrm{z}}\end{array}$ & & $\begin{array}{c}\text { Total } \\
\text { pore space } \\
(\% \mathrm{v} / \mathrm{v})\end{array}$ & $\begin{array}{c}\text { Air-filled } \\
\text { pore space } \\
(\% \mathrm{v} / \mathrm{v})\end{array}$ & $\begin{array}{c}\text { Water-holding } \\
\text { capacity } \\
(\% \mathrm{v} / \mathrm{v})\end{array}$ & $\begin{array}{c}\text { Bulk } \\
\text { density } \\
\left(\mathrm{g} \cdot \mathrm{cm}^{-3}\right)^{\mathrm{y}} \\
\end{array}$ \\
\hline $20 \%$ perlite & & 79.4 & 9.5 & 67.9 & 0.108 \\
\hline $30 \%$ perlite & & 76.9 & 10.8 & 68.9 & 0.101 \\
\hline $40 \%$ perlite & & 73.9 & 11.4 & 62.6 & 0.098 \\
\hline $50 \%$ perlite & & 73.9 & 11.9 & 62.8 & 0.115 \\
\hline $60 \%$ perlite & & 71.5 & 12.7 & 59.0 & 0.121 \\
\hline $20 \% \mathrm{PBH}$ & & 83.2 & 11.5 & 71.7 & 0.098 \\
\hline $30 \% \mathrm{PBH}$ & & 85.5 & 20.3 & 64.9 & 0.098 \\
\hline $40 \% \mathrm{PBH}$ & & 86.0 & 28.8 & 56.9 & 0.097 \\
\hline $50 \% \mathrm{PBH}$ & & 86.7 & 34.0 & 53.9 & 0.104 \\
\hline $60 \% \mathrm{PBH}$ & & 82.1 & 37.8 & 45.1 & 0.112 \\
\hline Significance & df & & & & \\
\hline Substrate & 9 & $* * *$ & $* * *$ & $* * *$ & $* * *$ \\
\hline Perlite vs. PBH & 1 & $* * *$ & $* * *$ & $* * *$ & *** \\
\hline $20 \%$ perlite vs. $\mathrm{PBH}$ & 1 & $* * *$ & NS & * & *** \\
\hline $30 \%$ perlite vs. $\mathrm{PBH}$ & 1 & $* * *$ & $* * *$ & * & ** \\
\hline $40 \%$ perlite vs. $\mathrm{PBH}$ & 1 & $* * *$ & $* * *$ & $* * *$ & NS \\
\hline $50 \%$ perlite vs. $\mathrm{PBH}$ & 1 & $* * *$ & $* * *$ & $* * *$ & *** \\
\hline $60 \%$ perlite vs. $\mathrm{PBH}$ & 1 & $* * *$ & *** & *** & ** \\
\hline
\end{tabular}

${ }^{\mathrm{z}}$ Substrate composition indicates percentage perlite or $\mathrm{PBH}$, with the remainder of substrate being sphagnum peat. y $1 \mathrm{~g} \cdot \mathrm{cm}^{-3}=0.5780 \mathrm{oz} /$ inch $^{3}$

Ns, ${ }^{*, * *, * * *}$ Nonsignificant or significant at $P=0.05,0.01$, or 0.001 respectively. $\mathrm{PBH}$, parboiled fresh rice hulls.

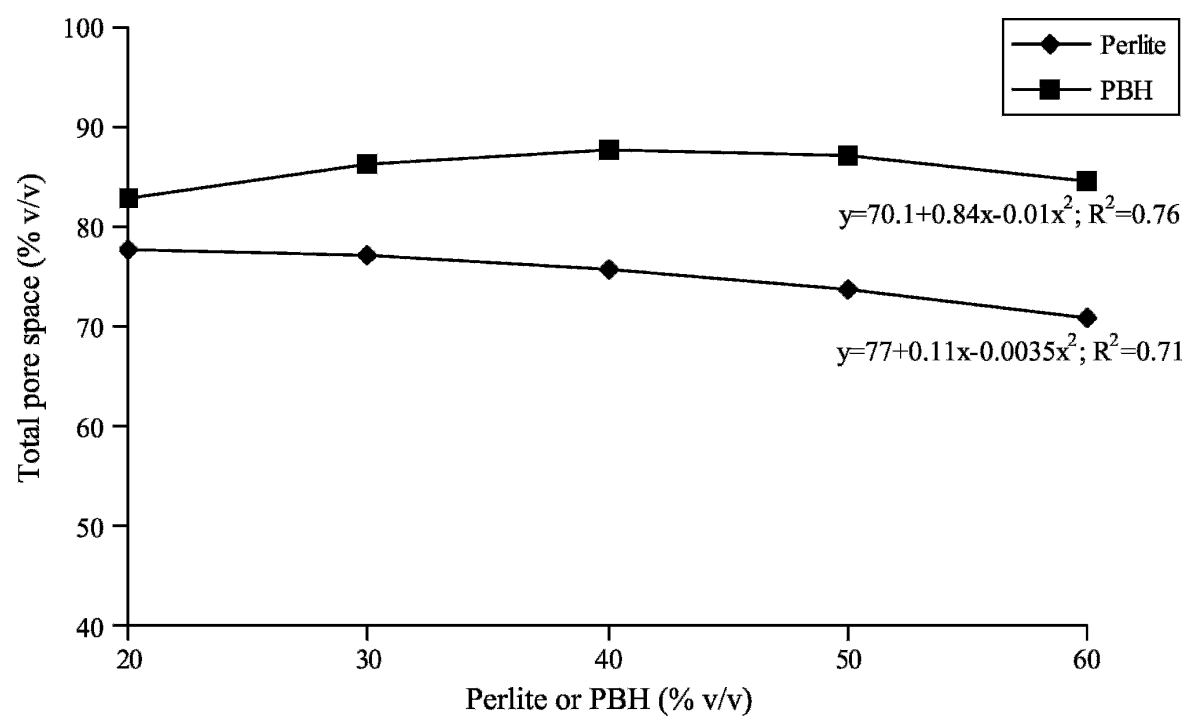

Fig. 1. Total pore space (\% by volume) of sphagnum peat-based root substrates containing $20 \%$ to $60 \%$ perlite or parboiled fresh rice hulls $(\mathrm{PBH})$. 
The air-filled pore space was not different between substrates containing $20 \%$ perlite or $\mathrm{PBH}$. However, the air-filled pore space was higher in $\mathrm{PBH}$-containing root substrates than in equivalent perlite-containing substrates when the amount of $\mathrm{PBH}$ or perlite was at least $30 \%$. As the amount of perlite increased, the airfilled pore space increased (Fig. 2), following the model $\mathrm{y}=7.94+0.08 \mathrm{x}$ $\left(R^{2}=0.76\right)$. As the amount of PBH increased, the air-filled pore space increased, following the model $\mathrm{y}=$ $1.11+0.62 \times\left(R^{2}=0.95\right)$.

Perlite had an air-filled pore space of $54 \%$ whereas $\mathrm{PBH}$ had an air-filled pore space of $69 \%$ (Hanan, 1998). The higher air-filled pore space of $\mathrm{PBH}$ could at least partially account for the higher air-filled pore space of $\mathrm{PBH}$-containing substrates overall, and specifically in substrates containing at least $30 \% \mathrm{PBH}$. The airfilled pore space of $\mathrm{PBH}$-containing substrates also increased at a higher rate (slope, 0.62) compared with perlite-containing substrates (slope, 0.08 ). The difference in the rate of change in air-filled pore space may have been partially the result of the higher air-filled pore space of $\mathrm{PBH}$, but also the result of the elongated shape of $\mathrm{PBH}$ (in contrast to perlite granules, which are generally spherical), which allowed the individual hulls to cross connect and create more and larger pores in substrates containing high concentrations of $\mathrm{PBH}$.

Water-holding capacity ranged from $59.0 \%$ to $68.9 \%$ for the perlitecontaining substrates and $45.1 \%$ to $71.7 \%$ for the $\mathrm{PBH}$-containing substrates (Table 1). The $20 \% \mathrm{PBH}^{-}$ containing substrate had a higher water-holding capacity than the $20 \%$ perlite-containing substrate. However, at $30 \%$ or more $\mathrm{PBH}$, the $\mathrm{PBH}-$ containing root substrates had a lower water-holding capacity than equivalent perlite-containing substrates. As the percentage perlite increased, the water-holding capacity decreased, following the model $\mathrm{y}=74-0.24 \mathrm{x}$ $\left(R^{2}=0.85\right)$. As the percentage $\mathrm{PBH}$ increased (Fig. 3), the water-holding capacity decreased, following the model $\mathrm{y}=84.2-0.62 \mathrm{x}\left(R^{2}=0.98\right)$.

As would have been expected, water-holding capacity was generally inversely related to air-filled pore space. As air-filled pore space increased, the water-filled pores, and thus water-

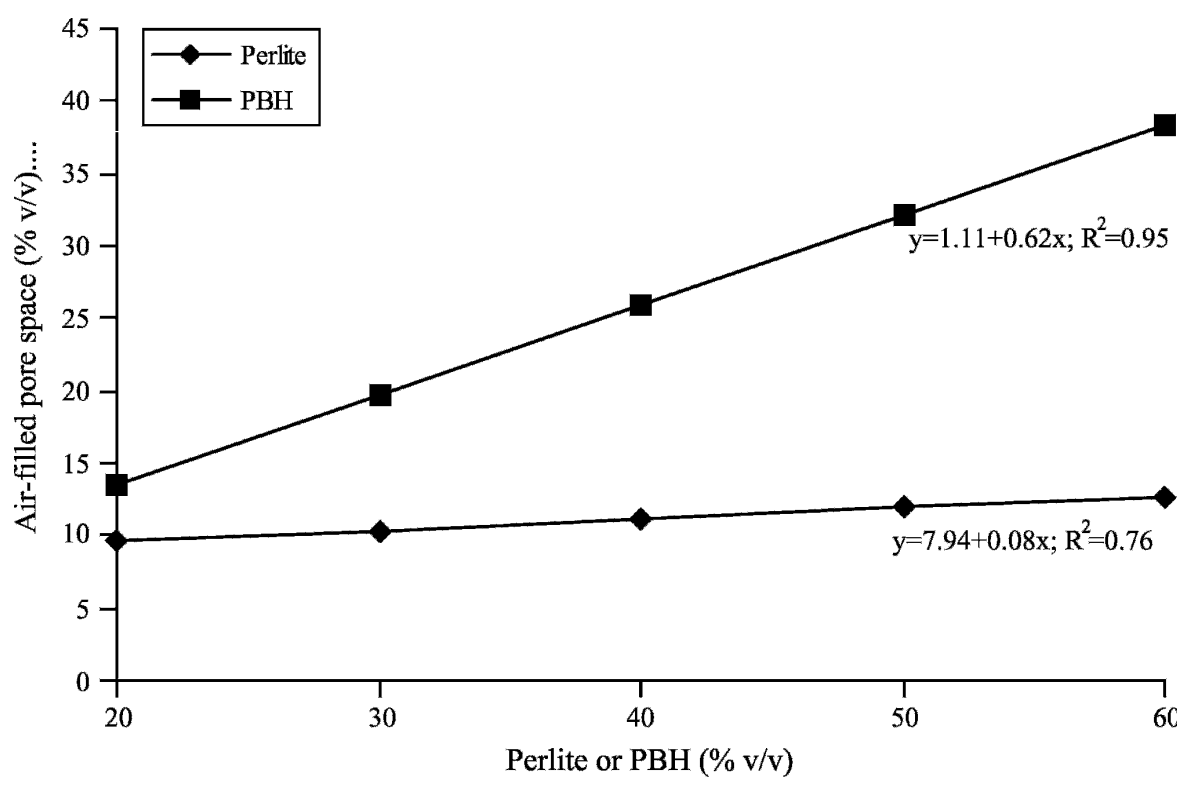

Fig. 2. Air-filled pore space (\% by volume) of sphagnum peat-based root substrates containing $20 \%$ to $60 \%$ perlite or parboiled fresh rice hulls $(\mathrm{PBH})$.

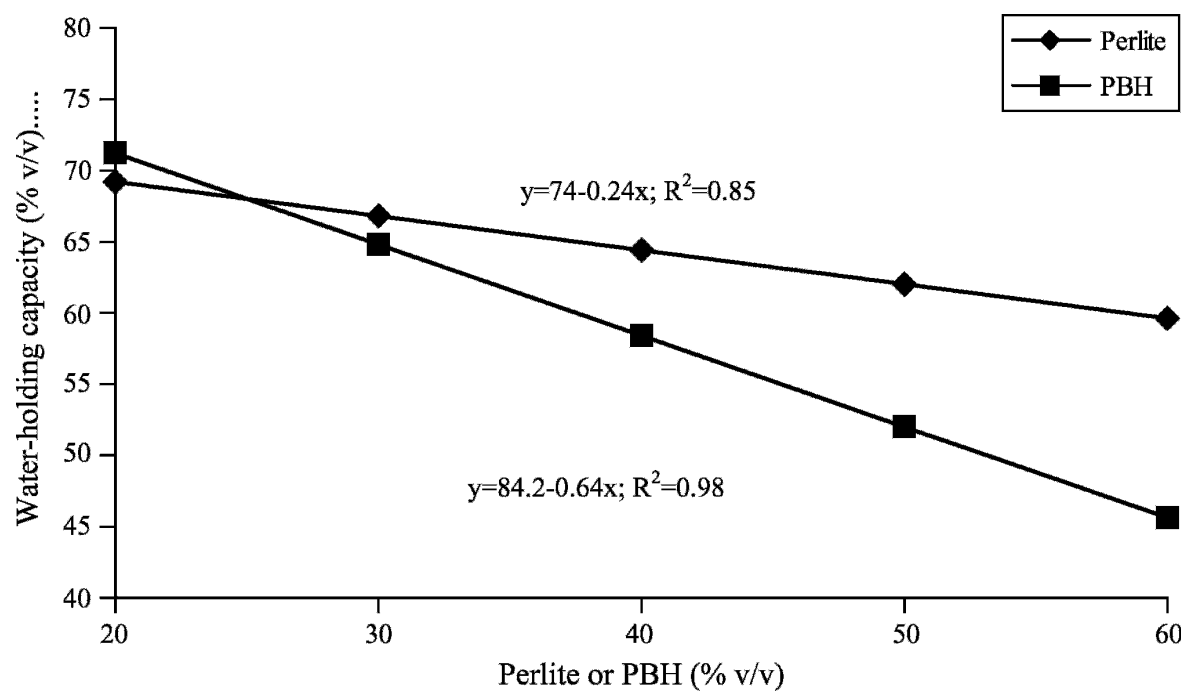

Fig. 3. Water-holding capacity (\% by volume) of sphagnum peat-based root substrates containing $20 \%$ to $60 \%$ perlite or parboiled fresh rice hulls $(\mathrm{PBH})$.

holding capacity, decreased. The properties of $\mathrm{PBH}$ - namely, particle size and shape - that resulted in a higher air-filled pore space, and a higher rate of change in air-filled pore space with increasing amounts of $\mathrm{PBH}$ also resulted in a lower water-holding capacity and a higher rate of decline (a slope of -0.24 for perlite and -0.64 for $\mathrm{PBH}$ ) in the water-holding capacity as $\mathrm{PBH}$ concentration increased compared with equivalent perlitecontaining substrates.

An anomaly in the data for waterholding capacity was that at $20 \%, \mathrm{PBH}$ had a higher water-holding capacity than the equivalent perlite-containing substrate. This was despite the fact that the $20 \% \mathrm{PBH}$ substrate had a higher total pore space and a similar air-filled pore space as the $20 \%$ perlite substrate. This anomaly could be a data artifact or could be the result of the shape of $\mathrm{PBH}$. In addition to being elongated, $\mathrm{PBH}$ have a "canoe" shape that catches water if oriented correctly. At low concentrations of $\mathrm{PBH}$, this might have resulted in additional water-holding capacity of the $\mathrm{PBH}$-containing substrate. However, as the amount of $\mathrm{PBH}$ was increased, the cross-linking of $\mathrm{PBH}$ that created more and larger pore spaces (and higher air-filled pore spaces) in the substrate would have more than compensated for this 
phenomenon, and the water-holding capacity would then begin to decline to less than that of the equivalent perlite-containing substrates.

Bulk densities ranged from 0.098 to $0.121 \mathrm{~g} \cdot \mathrm{cm}^{-3}$ for perlitecontaining substrates and 0.097 to $0.112 \mathrm{~g} \cdot \mathrm{cm}^{-3}$ for $\mathrm{PBH}$-containing substrates (Table 1). Except for substrates containing $40 \%$ perlite or $\mathrm{PBH}$, which had similar bulk densities, the bulk densities of perlite-containing substrates were more than the bulk densities of equivalent $\mathrm{PBH}$ substrates. For perlite-containing substrates, bulk density decreased (Fig. 4) as the amount of perlite was increased to $40 \%$, and then increased with increasing amounts of perlite, following the model $\mathrm{y}=0.14-002 \mathrm{x}+0.00004 \mathrm{x}^{2}$ $\left(R^{2}=0.85\right)$. For PBH-containing substrates, bulk density was generally unchanged until the amount of $\mathrm{PBH}$ increased to more than $40 \%$, at which point bulk density increased, following the model $\mathrm{y}=0.112-001 \mathrm{x}+$ $0.00002 \mathrm{x}^{2}\left(R^{2}=0.98\right)$.

Overall, and for all contrasts except for $40 \%$, PBH-containing substrates had a lower bulk density than perlite-containing substrates. Because perlite and $\mathrm{PBH}$ had similar bulk densities of $0.10 \mathrm{~g} \cdot \mathrm{cm}^{-3}$, the differences in bulk density may be a result of how the components packed when blended together, with the elongated shape of the PBH creating more pore space and resisting settling more than perlite. Additionally, horticultural perlite typically contains fine particles that may fill in pores and increase root

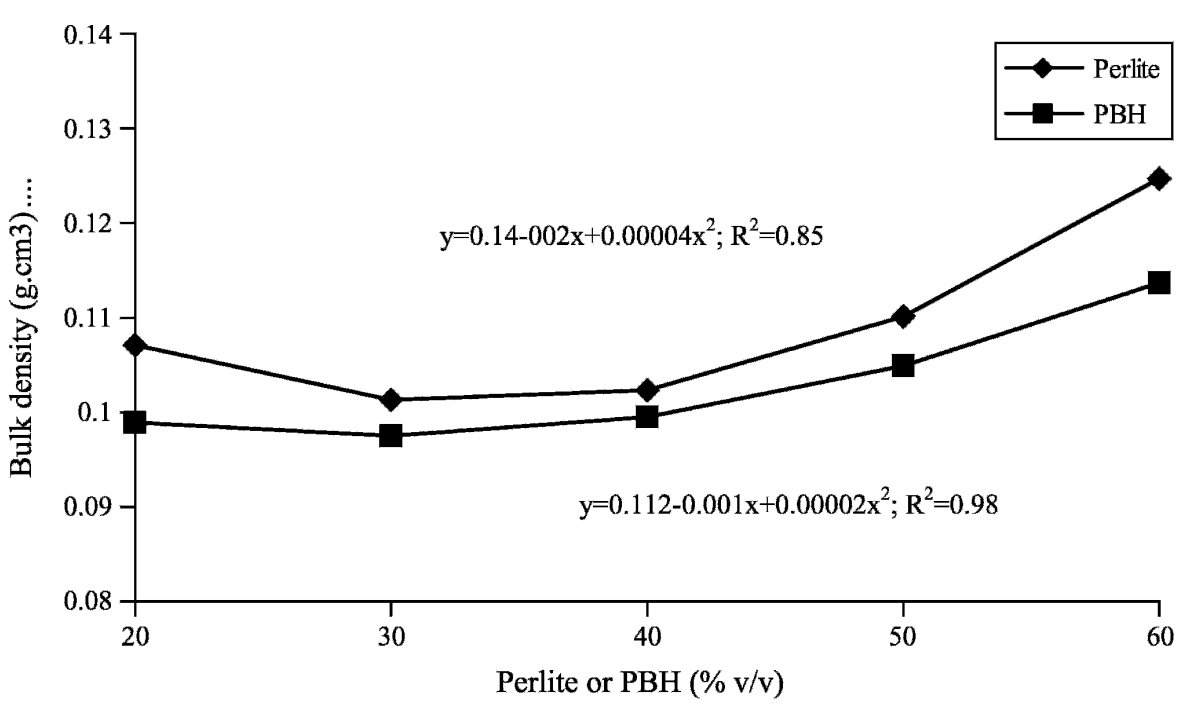

Fig. 4. Bulk density of sphagnum peat-based root substrates containing $20 \%$ to $60 \%$ perlite or parboiled fresh rice hulls $(\mathrm{PBH}) .1 \mathrm{~g} \cdot \mathrm{cm}^{-3}=0.5780 \mathrm{oz} / \mathrm{inch}^{3}$.

substrate bulk density. The decrease in bulk density at $40 \% \mathrm{PBH}$ or perlite may have been the result of how the different substrates settled or packed, or might have been a data artifact as a result of the small values that are measured when determining bulk density.

The differences in bulk densities were not great enough to be of practical significance and were all similar to that of sphagnum peat $(0.11$ $\mathrm{g} \cdot \mathrm{cm}^{-3}$ ) or within the range recommended by Jenkins and Jarrell (1989). Unlike materials such as calcined clay, bulk density of $\mathrm{PBH}$ would be acceptable and would not add to shipping costs of the substrates or plants grown in the substrates.

\section{Conclusion}

The inclusion of $\mathrm{PBH}$ provided for increased and air-filled pore space and drainage in the sphagnum peatbased substrates. Furthermore, increasing the amount of $\mathrm{PBH}$ in the substrate resulted in a greater increase in air-filled pore space and a greater decrease in the water-holding capacity than an equivalent amount of perlite. Therefore, PBH served a similar role in the substrate as perlite, but less $\mathrm{PBH}$ would be required in a substrate to provide the same air-filled pore space and water-holding capacity as perlite when more than $20 \%$ perlite or $\mathrm{PBH}$ was used.

Arnold Bik (1983) and Boertje (1984) recommended a minimum of $85 \%$ total pore space and at least $45 \%$ water-filled pore space. Bunt (1988) recommended an air-filled pore space

Hortechnology · July-September 2007 17(3) of at least $10 \%$ to $20 \%$. Jenkins and Jarrell (1989) proposed optimal ranges of $60 \%$ to $75 \%$ for total pore space, $50 \%$ to $65 \%$ for water-hold capacity, and $10 \%$ to $20 \%$ for air-filled pore space. All the perlite-containing substrates were within the recommended ranges for these parameters. Only substrates containing up to $30 \% \mathrm{PBH}$ had physical properties that were within these recommendations. However, in situations when a higher air-filled pore space and lower water-holding capacity (outside production in Florida) are desirable, substrates containing more than $30 \% \mathrm{PBH}$ would be suitable.

\section{Literature cited}

Arnold Bik, R. 1983. Substrates in floriculture. Proc. XXI Intl. Hort. Congr. 2:811-822.

Bilderback, T.E. and W.C. Fonteno. 1993. Impact of hydrogel on physical properties of coarse-structured horticultural substrates. J. Amer. Soc. Hort. Sci. 118:217-222.

Boertje, G.A. 1984. Physical laboratory analysis of potting composts. Acta Hort. 150:47-50.

Boertje, G.A. and R. Arnold Bik. 1975. Potting substrates in the Netherlands. Acta Hort. 106:149-158.

Bunt, A.C. 1988. Media and mixes for container grown plants. Unwin Hyman, London.

Byrne, P.J. and B. Carty. 1989. Developments in the measurement of air filled porosity of peat substrates. Acta Hort. 238:37-44.

Evans, M.R. 2004. Ground bovine bone as a perlite alternative in horticultural substrates. HortTechnology 14:171-175.

Evans, M.R. and M. Gachukia. 2004. Fresh parboiled rice hulls serve as an alternative to perlite in greenhouse crop substrates. HortScience 39:232-235.

Evans, M.R. and R.L. Harkess. 1997. Growth of Pelargonium $\times$ hortorum and Eurphorbia pulcherrima in rubber-containing substrates. HortScience 32:874-877.

Hanan, J.J. 1998. Greenhouse-advanced technology for protected horticulture. CRC Press, Boca Raton, Fla.

Jenkins, J.R. and W.M. Jarrell. 1989. Predicting physical and chemical properties of container mixtures. HortScience 24:292-295.

Nelson, P.V. 2003. Greenhouse operation and management, 6th ed. Prentice Hall, Upper Saddle River, N.J. 